\title{
Predictors and correlates of serum 25-hydroxyvitamin D concentrations in young women: results from the Safe-D study
}

\author{
Emma T. Callegari ${ }^{1}$, Suzanne M. Garland ${ }^{2,3,4}$, Alexandra Gorelik ${ }^{5}$, Nicola J. Reavley ${ }^{6}$ and John D. Wark ${ }^{1,7 *}$ \\ on behalf of the Safe-D study team \\ ${ }^{1}$ Department of Medicine, Royal Melbourne Hospital, The University of Melbourne, Parkville, VIC 3050, Australia \\ ${ }^{2}$ Department of Obstetrics and Gynaecology, The University of Melbourne, Parkville, VIC 3010, Australia \\ ${ }^{3}$ Murdoch Childrens Research Institute, Parkville, VIC 3052, Australia \\ ${ }^{4}$ Royal Women's Hospital, Parkville, VIC 3052, Australia \\ ${ }^{5}$ Melbourne EpiCentre, Royal Melbourne Hospital, University of Melbourne, Parkville, VIC 3050, Australia \\ ${ }^{6}$ Melbourne School of Population and Global Health, The University of Melbourne, Parkville, VIC 3010, Australia \\ ${ }^{7}$ Bone and Mineral Medicine, Royal Melbourne Hospital, Parkville, VIC 3050, Australia.
}

(Submitted 19 January 2017 - Final revision received 1 July 2017 - Accepted 14 July 2017)

\section{Abstract}

Vitamin D deficiency is a global public health concern. Studies of serum 25-hydroxyvitamin D (25(OH)D) determinants in young women are limited and few include objective covariates. Our aims were to define the prevalence of vitamin D deficiency and examine serum 25(OH)D correlates in an exploratory study of women aged 16-25 years. We studied 348 healthy females living in Victoria, Australia, recruited through Facebook. Data collected included serum 25(OH)D assayed by liquid chromatography-tandem MS, relevant serum biochemistry, soft tissue composition by dual-energy X-ray absorptiometry, skin melanin density, Fitzpatrick skin type, sun exposure using UV dosimeters and lifestyle factors. Mean serum 25(OH)D was 68 (sD 27) nmol/l and 26\% were vitamin D deficient (25(OH)D <50 nmol/l). The final model explained 56\% of $25(\mathrm{OH}) \mathrm{D}$ variance. Serum sex hormone-binding globulin levels, creatinine levels, sun exposure measured by UV dosimeters, a positive attitude towards sun tanning, typically spending $>2 \mathrm{~h}$ in the sun in summer daily, holidaying in the most recent summer period, serum Fe levels, height and multivitamin use were positively associated with $25(\mathrm{OH}) \mathrm{D}$. Fat mass and a blood draw in any season except summer was inversely associated with $25(\mathrm{OH}) \mathrm{D}$. Vitamin D deficiency is common in young women. Factors such as hormonal contraception, sun exposure and sunrelated attitudes, as well as dietary supplement use are essential to consider when assessing vitamin D status. Further investigation into methods to safely optimise vitamin D status and to improve understanding of the impact of vitamin D status on long-term health outcomes is required.

Key words: 25-Hydroxyvitamin D: MS/MS: Young women

Vitamin D is a precursor of a system of hormones that assists in the active absorption of $\mathrm{Ca}$, thereby facilitating skeletal mineralisation. Exposure to UV radiation (UVR) from the sun increases vitamin D synthesis in the skin, which is the source of approximately $90 \%$ of circulating vitamin D in the body ${ }^{(1)}$. Few foods naturally contain vitamin D. Thus, only small amounts of vitamin $\mathrm{D}$ are usually obtained through diet. Vitamin $\mathrm{D}$ is metabolised in the liver to form 25-hydroxyvitamin D (25(OH)D), the major circulating metabolite. Serum $25(\mathrm{OH}) \mathrm{D}$ is then converted in the kidney into the highly active metabolite 1,25-dihydroxyvitamin D (1,25D). Serum 25(OH)D levels are used to determine vitamin $\mathrm{D}$ status as this biomarker reflects both dietary intake (food, supplements) and endogenously synthesised vitamin D. Serum 25(OH)D has a much longer half-life than $1,25 \mathrm{D}$, implying that it is the more stable metabolite. Circulating 25(OH)D levels are almost 1000-fold more than $1,25 \mathrm{D}$, making $25(\mathrm{OH}) \mathrm{D}$ the major circulating substrate. The liver has a high capacity for 25-hydroxylation, which is loosely regulated compared with the production of $1,25 \mathrm{D}$ in the kidneys ${ }^{(2)}$. Therefore, vitamin D nutritional status is better reflected by the more available substrate, $25(\mathrm{OH}) \mathrm{D}$.

Adolescence and young adulthood are critical times in a young woman's life as independent behaviours and lifestyle choices are established ${ }^{(3)}$. These choices made as an emerging adult lay the foundation for future health trajectories not only for individuals but also for their future partners and families ${ }^{(4)}$. Vitamin D deficiency (VDD) is more common in females than males $^{(5)}$. In adults, inadequate $25(\mathrm{OH}) \mathrm{D}$ impacts adversely on

Abbreviations: 25(OH)D, 25-hydroxyvitamin D; COC, combined oral contraceptive pill; IQR, interquartile range; PTH, parathyroid hormone; SEIFA, Socio-Economic Indexes for Areas; SHBG, sex hormone-binding globulin; VDD, vitamin D deficiency.

* Corresponding author: Professor J. D. Wark, fax +6139347 1863, email jdwark@unimelb.edu.au 
musculoskeletal health (e.g. osteoporosis, secondary hyperparathyroidism, osteomalacia). Observational studies suggest that VDD during pregnancy may also be a risk factor for a number of reproductive health outcomes. Therefore, serum $25(\mathrm{OH}) \mathrm{D}$ concentrations of $>50 \mathrm{nmol} / \mathrm{l}$ are recommended by the WHO, National Institutes of Health and the Royal Australia New Zealand College of Obstetricians and Gynaecologists ${ }^{(6)}$. Clinical, behavioural and lifestyle factors associated with vitamin D status in young females of child-bearing age require further attention as previous studies have focused largely on elderly populations, where the risk factors for and consequences of chronically low vitamin D levels are better established. A better understanding of the determinants of vitamin D status and addressing VDD in young women are likely to improve their overall well-being, productivity and long-term health outcomes, as well as the health of their potential future offspring.

Serum 25(OH)D has been most commonly been found to correlate with season, personal sun exposure, obesity and demographic factors such as age, country of birth or socioeconomic status $^{(5,7)}$. Less commonly, concentrations have been associated with cardiometabolic markers such as lipids and markers of insulin resistance ${ }^{(8)}$, creatinine levels ${ }^{(9)}$ and medication use including hormonal contraception ${ }^{(10)}$, which may be interlinked with changes in reproductive hormones.

Studies assessing vitamin D status in young Australian adults have previously been limited to clinical populations (e.g. oncology, psychiatry) or have focused on associations with a specific health outcome, such as CVD risk. Despite large sample sizes, other studies have had relatively small sample sizes across the late adolescent and young adult age range ${ }^{(5,11-13)}$. Therefore, the first objective of this study was to examine the prevalence of VDD, defined as serum $25(\mathrm{OH}) \mathrm{D}<50 \mathrm{nmol} / \mathrm{l}$, in a community sample of young women aged $16-25$ years. The second aim was to explore the clinical, demographic and lifestyle determinants of vitamin D status in this under-represented demographic.

\section{Methods}

\section{Study design and population}

Part A of the Safe-D study was a cross-sectional study of vitamin D and related health in females aged 16-25 years at the time of recruitment, living in Victoria, Australia (latitude 34-39 $\mathrm{S}$ ). A detailed description of the study methodology has been reported elsewhere ${ }^{(14)}$. In brief, participants were recruited through the online social networking site, Facebook. Individuals were recruited into the study if they were able to provide verbal and written consent, and complete all three components of the study: an online questionnaire, wearing an UV dosimeter for 14 consecutive days and a study site visit, including phlebotomy. Pregnant or breast-feeding women were excluded from the study.

\section{Ethics}

The study was approved by the Melbourne Health Human Research Ethics Committee, Melbourne Health, Victoria, Australia (project no. 2013.007). The study was carried out in accordance with the National Statement on Ethical Conduct in Research Involving Humans (2007) produced by the National Health and Medical Research Council of Australia (NHMRC). The study was supported by NHMRC project grant APP1049065.

\section{Online questionnaire}

Participants were emailed links to an extensive, online questionnaire $^{(14)}$. Demographic, health and lifestyle information collected included date of birth, country of birth, location of residence, education level, hormonal contraception including combined oral contraceptive pill (COC) use, self-reported Fitzpatrick skin type that categorises an individual's skin type by their response to sun exposure (e.g. skin type I represents skin that always burns, rarely tans and is pale white, whereas skin type VI never burns and is deeply pigmented) ${ }^{(15)}$, sun behaviours (exposure, sun-protection measures and tanning preference), physical activity using a modified Active Australia Survey ${ }^{(16)}$, smoking status, vitamin D supplementation and multivitamin use. Daily alcohol consumption and Ca intake were sourced from the Cancer Council Victoria FFQ, which collects data on usual eating habits in the past 12 months ${ }^{(17)}$. A sun tanning attitude score was calculated from a range of statements relating to tanning behaviour ${ }^{(18)}$. The statements included the following: (1) I feel more healthy with a suntan, (2) a suntan makes me feel more attractive to others, (3) this coming summer I intend to sunbathe regularly to get a suntan, (4) most of my friends think that a suntan is a good thing, (5) a suntan makes me feel better about myself, (6) most of my close family think that a suntan is a good thing and (7) a suntan protects you against melanoma and other skin cancers. The higher the score the more likely the participant felt positively about sun tanning. A score for the use of sun-protection measures was calculated from responses to how often a participant: (1) sought shade between 11.00 and 16.00 hours, (2) covered their head, (3) wore clothing to protect their skin from the sun, (4) wore sunglasses and (5) used sunscreen on skin exposed to the sun. These questions were adapted from the Cancer Council Australia SunSmart recommendations 'Slip Slop Slap Seek Slide ${ }^{,(19)}$. A higher sun-protection score indicated that a participant was less likely to regularly use sun-protection measures.

\section{Sun exposure}

Personal, real-time UVR exposure was measured using UV dosimeters developed at the National Institute of Water and Atmospheric Research in New Zealand (Scienterra). Dosimeters were set up and calibrated at the Australian Radiation Protection and Nuclear Safety Agency (ARPANSA). Data from the UV dosimeter were downloaded and analysed to calculate the average standard erythemal dose (SED) for each participant for the previous fortnight $\left(1 \mathrm{SED}=100 \mathrm{~J} / \mathrm{m}^{2}\right)$.

\section{Biochemical measures}

Participants were instructed to fast overnight for a minimum of $8 \mathrm{~h}$ before their allocated site visit. Site visits were conducted in the morning between 08.00 and 11.00 hours at the Royal 
Melbourne Hospital, Parkville, Australia. Blood samples were processed by the Melbourne Health Shared Pathology Service. Serum biochemistry was measured using an Abbott ARCHITECT c16000 integrated system (Abbott Diagnostics) in real time. Parathyroid hormone (PTH) was measured using an Abbott ARCHITECT i2000 SR immunoassay connected to a FlexLab track (Abbott Diagnostics). The CV for PTH was $4.7 \%$ at $2.90 \mathrm{pmol} / \mathrm{l}$.

A serum aliquot was stored at $-80^{\circ} \mathrm{C}$ for $25(\mathrm{OH}) \mathrm{D}$ analysis $\left(25(\mathrm{OH}) \mathrm{D}_{3}\right.$ plus $\left.25(\mathrm{OH}) \mathrm{D}_{2}\right)$, which was measured using liquid chromatography-tandem MS (LC-MS/MS) at VivoPharm Laboratories. The $\mathrm{D}_{2}$ metabolite had a detection limit of $4.91 \mathrm{nmol} / 1$, whereas for $25(\mathrm{OH}) \mathrm{D}_{3}$ it was $6.71 \mathrm{nmol} / 1$. Tri-Level Vitamin D metabolite Quality Control samples from UTAK Laboratories (PM Separations) were used for quality control in each assay run. The $\mathrm{CV}$ for $25(\mathrm{OH}) \mathrm{D}_{3}$ was $2.0 \%$ at $24.74 \mathrm{nmol} / \mathrm{l}$, $1.6 \%$ at $72.72 \mathrm{nmol} / 1$ and $1.4 \%$ at $163.33 \mathrm{nmol} / \mathrm{l}$. The $\mathrm{CV}$ for $25(\mathrm{OH}) \mathrm{D}_{2}$ was $4.9 \%$ at $21.35 \mathrm{nmol} / 1,2.5 \%$ at $63.48 \mathrm{nmol} / 1$ and $2 \cdot 5 \%$ at $152 \cdot 47 \mathrm{nmol} / 1$

\section{Physical measurements}

Height and weight were measured using standard procedures, from which BMI (BMI) was calculated $\left(\mathrm{kg} / \mathrm{m}^{2}\right)$ and categorised according to WHO criteria. Cutaneous melanin density was measured at the upper inner arm, hand and cheek using a CM-2500d Konica Minolta portable spectrophotometer (Konica Minolta) coupled with a skin analysis program (CM-SA; Konica Minolta Sensing Inc.) ${ }^{(20)}$.

\section{Dual-energy X-ray absorptiometry}

Dual-energy X-ray absorptiometry (DXA; QDR 4500 A densitometer; Hologic Inc.) was used to quantify body fat as a percentage of body weight, fat mass and lean mass. Scans were analysed using QDR software version 9.1D.

\section{Statistical analysis}

Participants were excluded from the analysis if they had not completed the medical history section of the questionnaire, had abnormal pathology results, were previously diagnosed with relevant medical conditions, had undergone relevant surgery, were taking medication/s that may affect 25(OH)D levels or had a diagnosis of osteoporosis before commencing the study. VDD was defined as serum 25(OH)D level $<50 \mathrm{nmol} / \mathrm{l}$ according to the Australian and New Zealand Bone and Mineral Society (ANZBMS) position statements ${ }^{(21,22)}$. This cut-off is supported by the Endocrine Society of Australia, Osteoporosis Australia and The National Academy of Medicine (formerly the Institute of Medicine). The 2005 ANZBMS position statements further categorises deficiency as mild (25(OH)D 25-50 nmol/l), moderate $(12.5-25 \mathrm{nmol} / \mathrm{l})$ or severe $(<12.5 \mathrm{nmol} / \mathrm{l})^{(21)}$

Each of the following factors was categorised as follows: country of birth as Australia or elsewhere; education as high school only or further education; location of residence as urban or regional; season as summer (December-February), autumn (March-May), winter (June-August) or spring (SeptemberNovember); BMI category as underweight $\left(<18.5 \mathrm{~kg} / \mathrm{m}^{2}\right)$, normal $\left(18.5-24.9 \mathrm{~kg} / \mathrm{m}^{2}\right)$, overweight $\left(25-29.9 \mathrm{~kg} / \mathrm{m}^{2}\right)$ and obese $\left(>30 \mathrm{~kg} / \mathrm{m}^{2}\right)$; Fitzpatrick skin type as type I-IV and V-VI; COC use as yes/no; physical activity as minimal-low (0-599 metabolic equivalent of task (MET)-min) or moderate-high levels (600 + MET-min); daily alcohol consumption as 0, 1-14, 15-29 or $\geq 30$ g; smoking as current smoker or ex-/non-smoker; vitamin D supplementation in the last 2 weeks as yes/no; use of a multivitamin in the last 2 weeks as yes/no; $\mathrm{Ca}$ intake as above or below $1000 \mathrm{mg} / \mathrm{d}$; use of $\mathrm{SPF} 30+$ sunscreen use as yes/no; took a holiday in the most recent summer period as yes/no; and reported spending $>2 \mathrm{~h}$ in the sun on a typical day in summer or winter as yes/no. The Socio-Economic Indexes for Areas (SEIFA) percentile was used to determine socioeconomic status ${ }^{(23)}$.

Scatterplot smoothing (Lowess) curves were used to examine the relationships between serum $25(\mathrm{OH}) \mathrm{D}$ and continuous variables. Continuous variables were checked for normality using the Shapiro-Wilk test. Pearson's correlation was used to test associations between 25(OH)D levels and continuous variables that were normally distributed (Spearman's correlation was used for data that were not normally distributed). Either Student's $t$ test or an ANOVA was used to examine associations between serum $25(\mathrm{OH}) \mathrm{D}$ and categorical variables. A multivariate linear regression model was used to explore associations between serum 25(OH)D and relevant variables. Participants with data missing for a particular variable were excluded from analysis where that variable was required in analysis. A $P$ value of $<0.05$ was considered statistically significant. All statistical analysis was performed using StataSE 13 (StataCorp LP).

\section{Sample size}

It was necessary for the sample size for part A of the Safe-D study to provide sufficient eligible participants to recruit adequate numbers for part B of the study, a randomised-controlled trial aiming to assess the effectiveness of an mHealth-based behavioural intervention to improve $25(\mathrm{OH}) \mathrm{D}$ levels and related health in young women with $25(\mathrm{OH}) \mathrm{D}$ levels ranging from 25 to $75 \mathrm{nmol} / \mathrm{l}^{(24)}$. Sample-size calculations have been reported previously and yielded a recruitment target of 468 participants ${ }^{(14)}$. This sample size provides $80 \%$ power at a $5 \%$ significance level to detect small-medium effect sizes (Cohen's $d=0 \cdot 25-0 \cdot 30$ ) in outcome measures.

\section{Results}

In all, 557 participants were recruited into part A of the Safe-D study by November 2015. Serum 25(OH)D concentrations were available for 407 participants. We excluded fifty-nine participants for the following reasons (note: some participants fulfilled multiple exclusion criteria): the participant had not completed the medical history section of the questionnaire ( $n$ 4), corrected $\mathrm{Ca}>2.60 \mathrm{mmol} / \mathrm{l}$ ( $n$ 2), thyroid-stimulating hormone $<0.35 \mathrm{mIU} / 1$ ( $n$ 4), C-reactive protein $>10 \mathrm{mg} / \mathrm{l}$ ( $n$ 31), was previously diagnosed with one of the following conditions: hyperthyroidism ( $n$ 2), hypothyroidism ( $n$ 1), cystic fibrosis $(n 1)$, coeliac disease ( $n 8)$, inflammatory spondyloarthritis $(n 1)$, 
congenital heart defects ( $n$ 1), anorexia, bulimia or other eating disorders ( $n 7$ ), or malabsorption conditions ( $n$ 1), had undergone previous surgery potentially affecting relevant outcomes ( $n$ 3) and the participant was taking specific medications (prednisolone ( $n$ 3), hydroxychloroquine ( $n$ 1), phenothiazine ( $n$ 1) or immunosuppressive drugs $(n 1)$ ). Two participants were excluded as they were diagnosed with osteoporosis before commencing the study. After exclusions were applied, data for 348 (85\%) participants were included in the analysis. Adequate data for personal sun exposure measured by the UV dosimeters were available for $258(74 \%)$ participants.

\section{Participant characteristics}

Participant characteristics are presented in Table 1. In all, $84 \%$ of the participants were born in Australia. Participants born outside Australia ( $n 55)$ reported their country of birth as in Europe (31\%), New Zealand (7\%), China, Japan or in Southeast Asia (29\%), in Southern Asia (11\%), America or Canada (9\%), in South America ( $7 \%$ ) or in Africa ( $5 \%$ ). A third of the participants were educated to a high school level only, whereas $14 \%$ were from the lowest socioeconomic status quartile according to SEIFA.

\section{Vitamin D status and parathyroid hormone}

The prevalence of VDD in the Safe-D cohort was $26 \cdot 2 \%$. Less than $1 \%$ of the participants had severe deficiency $(25(\mathrm{OH}) \mathrm{D}$ $<12.5 \mathrm{nmol} / \mathrm{l}), 5.5 \%$ had moderate deficiency $(12.5-29.9 \mathrm{nmol} / \mathrm{l})$ and $20.4 \%$ had mild deficiency $(30-49.9 \mathrm{nmol} / \mathrm{l})$. In all, ten participants $(2.9 \%)$ had $25(\mathrm{OH}) \mathrm{D} \geq 125 \mathrm{nmol} / \mathrm{l}$. The mean serum 25(OH)D was $68(\mathrm{sD} 27) \mathrm{nmol} / \mathrm{l}$. A total of thirty-one samples $(9 \%)$ had detectable $25(\mathrm{OH}) \mathrm{D}_{2}$ with a median level of 6 (interquartile range (IQR) 5,7 ) nmol/l (Table 1). The median PTH concentration was $6(\mathrm{IQR} 4,7) \mathrm{pmol} / \mathrm{l}$. Serum 25(OH)D showed seasonal variations (see Fig. 1 and Table 3 ). The prevalence of VDD was $8 \%$ in summer, $25 \%$ in autumn, $37 \%$ in winter and $21 \%$ in spring $(P<0 \cdot 001)$.

Serum 25(OH)D was negatively correlated with PTH $(\rho=-0 \cdot 31$, $P<0.001 ;$ Table 2). The median PTH levels were 7.6 (IQR $5.8-9.4) \mathrm{pmol} / \mathrm{l}$ in participants with serum $25(\mathrm{OH}) \mathrm{D}<12.5 \mathrm{nmol} / \mathrm{l}$, $6 \cdot 2$ (IQR $5 \cdot 1-7 \cdot 8$ ) pmol/l with 25(OH)D 25-49.9 nmol/l, 5.5 (IQR $4 \cdot 4-7 \cdot 1$ ) pmol/1 with 25(OH)D $50-74.9 \mathrm{nmol} / 1$ and 4.7 (IQR 3.9-5.9) $\mathrm{pmol} / 1$ with $25(\mathrm{OH}) \mathrm{D}>75 \mathrm{nmol} / \mathrm{l}(P<0 \cdot 001)$.

\section{Association between 25-hydroxyvitamin D and demographic variables}

A negative association was found between serum $25(\mathrm{OH}) \mathrm{D}$ levels and chronological age (Table 2). Serum 25(OH)D and SEIFA percentile were positively associated (Table 2).

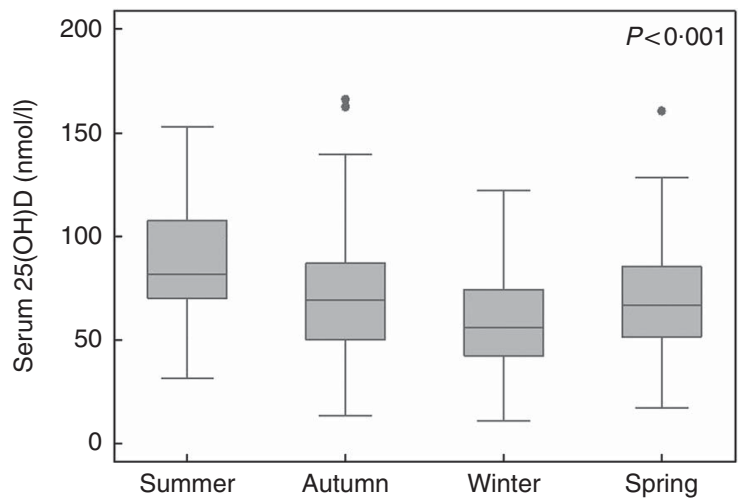

Fig. 1. Box plot of seasonal variations in 25-hydroxyvitamin $D(25(\mathrm{OH}) \mathrm{D})$ levels.

Table 1. Characteristics of Safe-D participants ( $n$ 348)

(Mean values and standard deviations; medians and interquartile ranges (IQR))

\begin{tabular}{|c|c|c|c|c|c|}
\hline Characteristics & Mean & SD & Median & IQR & Range \\
\hline Age (years) & 21.9 & $2 \cdot 8$ & & & $16 \cdot 3-26 \cdot 4$ \\
\hline \multicolumn{6}{|l|}{$25(\mathrm{OH}) \mathrm{D}$} \\
\hline $25(\mathrm{OH}) \mathrm{D}_{2}(\mathrm{nmol} / \mathrm{l})^{\star}$ & & & 6 & 5,7 & $5-12$ \\
\hline $25(\mathrm{OH}) \mathrm{D}_{3}(\mathrm{nmol} / \mathrm{l})$ & 65 & 27 & & & $9-164$ \\
\hline Total 25(OH)D (nmol/l) & 68 & 27 & & & $11-166$ \\
\hline PTH (pmol/l) & & & 6 & 4,7 & $2-19$ \\
\hline Body fat (\%) & $31 \cdot 2$ & $6 \cdot 2$ & & & $16 \cdot 1-50 \cdot 2$ \\
\hline $\mathrm{BMI}\left(\mathrm{kg} / \mathrm{m}^{2}\right)$ & 23.5 & $4 \cdot 1$ & & & $16 \cdot 7-42 \cdot 4$ \\
\hline \multicolumn{6}{|l|}{ Melanin density index } \\
\hline Upper, inner arm & & & 0.69 & $0.55,0.85$ & $0.32-2 \cdot 16$ \\
\hline Hand & & & 0.88 & $0.72,1.09$ & $0 \cdot 37-2 \cdot 20$ \\
\hline Facial cheek & & & 0.93 & $0.81,1.04$ & $0.52-2 \cdot 11$ \\
\hline Fitzpatrick skin type $\dagger$ & 3 & 1 & & & $1-5$ \\
\hline Daily personal sun exposure in previous 2 weeks (SED) & & & 1.89 & $1.09,3.47$ & $0.09-16.56$ \\
\hline Sun tanning attitude score $\neq$ & 22 & 8 & & & $7-42$ \\
\hline Sun-protection score§ & 13 & 3 & & & $5-23$ \\
\hline Physical activity (MET-min) & & & 1140 & 520,2085 & 0-9015 \\
\hline Alcohol consumption (g/d) & & & 3.0 & $0.5,9.3$ & $0-80.6$ \\
\hline Ca intake $(\mathrm{mg} / \mathrm{d})$ & 811 & 316 & & & $89-2864$ \\
\hline
\end{tabular}

25(OH)D, 25-hydroxyvitamin D; PTH, parathyroid hormone; SED, standard erythemal dose; MET, metabolic equivalent.

${ }^{*} 25(\mathrm{OH}) \mathrm{D}_{2}$ detected in thirty-one samples $(9 \%)$. The remaining samples were below the assay limit of detection.

† The minimum possible Fitzpatrick skin type is 1, whereas the maximum possible is 6 .

‡ The minimum possible sun tanning attitude score is 7 , whereas the maximum possible score is 42 .

$\S$ The minimum possible sun-protection score is 5 , whereas the maximum possible score is 25 . 
Table 2. Univariate associations between serum 25-hydroxyvitamin D and continuous variables in young women

\begin{tabular}{|c|c|c|c|}
\hline Variable & $r^{*}$ & $\rho \dagger$ & $P$ \\
\hline \multicolumn{4}{|l|}{ Demographic variables } \\
\hline Age (years) & -0.13 & & 0.014 \\
\hline SEIFA (\%) & 0.13 & & 0.015 \\
\hline \multicolumn{4}{|l|}{ Clinical variables } \\
\hline Melanin density of the hand & & 0.12 & 0.027 \\
\hline Height $(m)$ & 0.17 & & 0.002 \\
\hline BMI $\left(\mathrm{kg} / \mathrm{m}^{2}\right)$ & -0.14 & & 0.008 \\
\hline Fat mass (kg) & & -0.15 & 0.004 \\
\hline Body fat $(\%)$ & & -0.16 & 0.003 \\
\hline \multicolumn{4}{|l|}{ Lifestyle variables } \\
\hline Daily personal sun exposure (SED) & & 0.37 & $<0.001$ \\
\hline Sun tanning attitude score & 0.22 & & 0.001 \\
\hline $\begin{array}{l}\text { Reported number of times sunburnt } \\
\text { in the previous } 12 \text { months }\end{array}$ & 0.27 & & $<0.001$ \\
\hline \multicolumn{4}{|l|}{ Biomarkers } \\
\hline PTH (pmol/l) & & -0.31 & $<0.001$ \\
\hline Creatinine $(\mu \mathrm{mol} / \mathrm{l})$ & 0.34 & & $<0.001$ \\
\hline eGFR $\left(\mathrm{ml} / \mathrm{min} / 1.73 \mathrm{~m}^{2}\right)$ & -0.30 & & $<0.001$ \\
\hline $\mathrm{Hb}(\mathrm{g} / \mathrm{l})$ & 0.12 & & 0.033 \\
\hline Corrected serum $\mathrm{Ca}(\mathrm{mmol} / \mathrm{l}) \ddagger$ & $0 \cdot 18$ & & $<0.001$ \\
\hline Prolactin $(\mu \mathrm{mol} / \mathrm{l})$ & & -0.16 & 0.003 \\
\hline $\mathrm{SHBG}(\mathrm{nmol} / \mathrm{l})$ & & 0.34 & $<0.001$ \\
\hline $\mathrm{Fe}(\mu \mathrm{g} / \mathrm{l})$ & $0 \cdot 18$ & & 0.002 \\
\hline Transferrin $(\mu \mathrm{mol} / \mathrm{l})$ & $0 \cdot 18$ & & 0.002 \\
\hline TIBC $(\mu \mathrm{g} / \mathrm{l})$ & $0 \cdot 18$ & & 0.002 \\
\hline
\end{tabular}

SEIFA, Socio-Economic Indexes for Areas; SED, standard erythemal dose; PTH, parathyroid hormone; eGFR, estimated glomerular filtration rate; SHBG, sex hormone-binding globulin; TIBC, total Fe-binding capacity.

* Calculated using Pearson's correlation.

† Calculated using Spearman's correlation.

$\ddagger$ Serum Ca corrected for albumin. $\mathrm{Ca}+((40-$ albumin $) \times 0.02)$.

Participants born outside of Australia had, on average, $26 \mathrm{nmol} / \mathrm{l}$ lower 25(OH)D compared with Australian-born participants (Table 3). Participants with university or further education had, on average, $7 \mathrm{nmol} / 1$ lower 25(OH)D levels compared with those with high school education only (Table 3 ). No association was found between $25(\mathrm{OH}) \mathrm{D}$ levels and location of residence (urban $v$. rural; $P=0.095$; data not shown).

\section{Association between 25-hydroxyvitamin D and sun exposure}

A summary of sun exposure-related variables is presented in Table 1. In all, $7 \%$ of the participants had been sunburnt $>5$ times in the previous 12 months. In summer, $55 \%$ of the participants reported spending $>2 \mathrm{~h}$ in the sun on a typical day, whereas in winter $20 \%$ reported spending $>2 \mathrm{~h}$ in the sun daily. A total of $62 \%$ of the participants with adequate $25(\mathrm{OH}) \mathrm{D}$ levels reported spending $>2 \mathrm{~h}$ in the sun on a typical day in summer compared with $37 \%$ with VDD $(P<0 \cdot 001)$.

Serum $25(\mathrm{OH}) \mathrm{D}$ was positively associated with daily personal exposure measured by UV dosimetry $\left(R^{2}=0 \cdot 08\right.$; see online Supplementary Fig. S2), the sun tanning attitude score and reported number of times sunburnt in the previous 12 months (Table 2). In addition, serum 25(OH)D levels were higher in participants who reported spending $>2 \mathrm{~h}$ in the sun in summer on a typical day and in those who took a holiday in the most recent summer period (see Table 3). Serum 25(OH)D was not associated with spending $>2 \mathrm{~h}$ in the sun in winter $(P=0.098)$,
Table 3. Univariate associations between serum 25-hydroxyvitamin D $(25(\mathrm{OH}) \mathrm{D})$ and categorical variables in young women (Mean values and standard deviations)

\begin{tabular}{|c|c|c|c|c|}
\hline \multirow[b]{2}{*}{ Variable } & \multirow[b]{2}{*}{$n$} & \multicolumn{2}{|c|}{ 25(OH)D (nmol/l) } & \multirow[b]{2}{*}{$P^{*}$} \\
\hline & & Mean & SD & \\
\hline \multicolumn{5}{|l|}{ Demographic variables } \\
\hline Country of birth & & & & $<0.001$ \\
\hline Australia & 293 & 70 & 27 & \\
\hline Outside Australia & 55 & 56 & 27 & \\
\hline Education & & & & 0.021 \\
\hline High school only & 114 & 73 & 26 & \\
\hline University or further education & 229 & 66 & 27 & \\
\hline \multicolumn{5}{|l|}{ Clinical variables } \\
\hline Season of blood draw & & & & $<0.001$ \\
\hline Summer & 52 & 87 & 27 & \\
\hline Autumn & 68 & 72 & 32 & \\
\hline Winter & 139 & 58 & 2 & \\
\hline Spring & 89 & 69 & 25 & \\
\hline BMI category & & & & $<0.001$ \\
\hline Underweight & 18 & 54 & 23 & \\
\hline Normal & 231 & 72 & 28 & \\
\hline Overweight & 73 & 63 & 23 & \\
\hline Obese & 26 & 55 & 19 & \\
\hline Fitzpatrick skin type & & & & 0.016 \\
\hline I-IV & 328 & 69 & 27 & \\
\hline V-VI & 16 & 52 & 29 & \\
\hline COC use & & & & $<0.001$ \\
\hline Yes & 145 & 79 & 29 & \\
\hline No & 184 & 60 & 24 & \\
\hline \multicolumn{5}{|l|}{ Lifestyle variables } \\
\hline $\begin{array}{c}\text { Reported spending }>2 \mathrm{~h} \text { in } \\
\text { the sun in summer daily }\end{array}$ & & & & $<0.001$ \\
\hline Yes & 191 & 72 & 27 & \\
\hline No & 157 & 63 & 27 & \\
\hline $\begin{array}{l}\text { Took a holiday in the recent } \\
\text { summer period }\end{array}$ & & & & $<0.001$ \\
\hline Yes & 234 & 72 & 28 & \\
\hline No & 104 & 59 & 21 & \\
\hline Physical activity levels & & & & 0.009 \\
\hline Minimal-to-low & 99 & 62 & 24 & \\
\hline Moderate-to-high & 246 & 70 & 28 & \\
\hline Alcohol consumption (g) & & & & 0.018 \\
\hline 0 & 50 & 65 & 28 & \\
\hline $1-14$ & 246 & 66 & 25 & \\
\hline $15-29$ & 32 & 81 & 28 & \\
\hline$\geq 30$ & 12 & 75 & 31 & \\
\hline Multivitamin use in the previous week & & & & 0.002 \\
\hline Yes & 58 & 78 & 31 & \\
\hline No & 289 & 66 & 26 & \\
\hline $\begin{array}{l}\text { Vitamin D supplement use } \\
\text { in the previous week }\end{array}$ & & & & 0.066 \\
\hline Yes & 27 & 77 & 26 & \\
\hline No & 320 & 67 & 27 & \\
\hline
\end{tabular}

COC, combined oral contraceptive pill.

* Differences between groups were analysed using Student's $t$ test. If data were grouped into more than two groups ANOVA was used.

the sun-protection score $(P=0 \cdot 067)$ or the use of a sunscreen with SPF30 + or higher $(P=0 \cdot 416$; data not shown $)$.

\section{Association between 25-hydroxyvitamin D and other lifestyle variables}

Serum 25(OH)D levels were, on average, $8 \mathrm{nmol} / 1$ higher in participants who reported moderate-to-high physical activity levels compared with those who reported minimal-to-low activity levels (see Table 2). Serum 25(OH)D levels were 
Table 4. Stepwise regression model assessing a number of potential correlates of 25-hydroxyvitamin $D$ in young women* (Regression coefficients $(\beta)$ and $95 \%$ confidence intervals)

\begin{tabular}{|c|c|c|c|c|c|}
\hline Factors & Unadjusted $\beta \dagger$ & $\operatorname{Adj} \beta \dagger$ & $95 \% \mathrm{Cl}$ & $P$ & $R^{2}$ \\
\hline $\mathrm{SHBG}(\mathrm{nmol} / \mathrm{l})$ & $0 \cdot 11$ & 0.07 & $0.04,0.10$ & $<0.001$ & \\
\hline Creatinine $(\mu \mathrm{mol} / \mathrm{l})$ & 1.38 & 0.93 & $0.44,1.42$ & $<0.001$ & \\
\hline Personal sun exposure in previous 14 days (SED) & $25 \cdot 86$ & $10 \cdot 60$ & $1.29,19.91$ & 0.026 & \\
\hline Holiday taken in most recent summer period & 13.52 & $9 \cdot 15$ & $2 \cdot 17,16 \cdot 13$ & 0.011 & \\
\hline \multicolumn{6}{|l|}{ Season (summer reference) } \\
\hline Autumn & $-14 \cdot 19$ & -17.99 & $-27 \cdot 61,-8.37$ & $<0.001$ & \\
\hline Winter & $-17 \cdot 21$ & -31.83 & $-40 \cdot 64,-23.02$ & $<0.001$ & 0.56 \\
\hline Spring & -17.47 & -21.55 & $-32 \cdot 18,-10 \cdot 92$ & $<0.001$ & \\
\hline Fat mass $(\mathrm{kg})$ & -0.55 & -0.60 & $-1.01,-0.18$ & 0.005 & \\
\hline Multivitamin use & $12 \cdot 16$ & 12.96 & $4.62,21.30$ & 0.003 & \\
\hline Reported spending $>2 \mathrm{~h}$ in the sun in summer on a typical day & 9.41 & 7.84 & $1.59,14.09$ & 0.014 & \\
\hline $\mathrm{Fe}(\mu \mathrm{mol} / \mathrm{l})$ & 0.64 & 0.39 & $0.01,0.77$ & 0.043 & \\
\hline Height $(\mathrm{cm})$ & 0.70 & 0.62 & $0.12,1.12$ & 0.016 & \\
\hline Sun tanning attitude score & 0.73 & 0.40 & $0.04,0.77$ & 0.032 & \\
\hline
\end{tabular}

SHBG, sex hormone-binding globulin, COC, combined oral contraceptive pill; SED, standard erythemal dose.

* The following variables were entered into a single stepwise elimination regression model: age (years), Socio-Economic Indexes for Areas percentile, creatinine $(\mu \mathrm{mol} / \mathrm{l})$, estimated glomerular filtration rate $\left(\mathrm{ml} / \mathrm{min} / 1.73 \mathrm{~m}^{2}\right)$, corrected $\mathrm{Ca}(\mathrm{mmol} / \mathrm{l})$, prolactin $(\mu \mathrm{mol} / \mathrm{l})$, SHBG $(\mathrm{nmol} / \mathrm{l}), \mathrm{Hb}(\mathrm{g} / \mathrm{l})$, Fe $(\mu \mathrm{mol} / \mathrm{l})$, height $(\mathrm{m})$, fat mass $(\mathrm{kg})$, melanin density index of the hand, personal sun exposure measured using UV dosimeters (SED), sun tanning attitude score, reported number of times sunburnt in previous 12 months, country of birth, education, season, Fitzpatrick skin type V-VI, COC use, reported spending $>2 \mathrm{~h}$ in the sun in summer, reported going on holidays in the most recent summer period, physical activity, alcohol consumption and multivitamin use. $\dagger$ Estimates are given as nmol/l per unit of covariate.

lower in those who reported drinking $<15 \mathrm{~g}$ of alcohol daily or abstained from drinking (Table 3). Participants who had reported taking a multivitamin in the previous week had on average $12 \mathrm{nmol} / 1$ higher 25(OH)D levels than those who did not (Table 3). A trend towards higher $25(\mathrm{OH}) \mathrm{D}$ with vitamin D supplementation was observed, but did not reach statistical significance. Serum 25(OH)D levels were not associated with dietary $\mathrm{Ca}(P=0.172)$ or energy intake $(P=0.722)$ as continuous variables, nor were $25(\mathrm{OH}) \mathrm{D}$ levels associated with current smoking status $(P=0 \cdot 464$; data not shown).

\section{Association between 25-hydroxyvitamin D and biomarkers}

Serum $25(\mathrm{OH}) \mathrm{D}$ was positively associated with serum creatinine $\left(R^{2}=0 \cdot 11\right)$, Ca corrected for albumin, sex hormonebinding globulin (SHBG; $R^{2}=0 \cdot 15$ ), Fe, transferrin and TIBC values (Table 2). The positive association between 25(OH)D and creatinine remained significant after adjustment for lean mass and height $(\beta=1.4 ; 95 \%$ CI $0.99,1.84, \quad P<0.001)$. A positive trend was observed between $25(\mathrm{OH}) \mathrm{D}$ and transferrin saturation $(P=0.090$; data not shown). Serum 25(OH)D was inversely associated with estimated glomerular filtration rate and prolactin (Table 2). No association was observed between $25(\mathrm{OH}) \mathrm{D}$ and the following analytes: C-reactive protein $(\rho=0.05, P=0.357)$, thyroid stimulating hormone $(r 0.06$, $P=0.289)$, ferritin $(\rho=0.09, P=0.103)$, luteinising hormone ( $\rho=-0.05, P=0.547)$, follicle-stimulating hormone $(r-0.07$, $P=0.401)$, oestradiol $(\rho=-0.06, \quad P=0.466)$, progesterone ( $\rho=0.14, P=0.076)$, testosterone $(r 0.08, P=0.307)$ and dehydroepiandrosterone sulphate $(r-0 \cdot 03, P=0 \cdot 289)$.

\section{Association between 25-hydroxyvitamin D and clinical variables}

Serum 25(OH)D was positively associated with height, whereas $25(\mathrm{OH}) \mathrm{D}$ was negatively associated with percent body fat, BMI and fat mass (Table 2). Serum 25(OH)D levels were significantly lower in those who were categorised as either underweight or obese (Table 3). Serum 25(OH)D levels were on average $19 \mathrm{nmol} / \mathrm{l}$ higher in COC users compared with non-users $\left(R^{2}=0 \cdot 12\right.$; Table 3$)$. Serum 25(OH)D was not associated with body weight $(r-0 \cdot 10, P=0 \cdot 215)$, but tended to be positively associated with lean mass $(\rho=0 \cdot 10, P=0 \cdot 057)$.

Serum $25(\mathrm{OH}) \mathrm{D}$ was positively associated with melanin density of the hand (Table 2). No association was observed between $25(\mathrm{OH}) \mathrm{D}$ and melanin density of the upper, inner arm ( $\rho=-0.01, P=0.905)$ or facial cheek $(\rho=-0.02, P=0.654)$. A trend towards an association was observed between $25(\mathrm{OH}) \mathrm{D}$ levels and Fitzpatrick skin type $(P=0 \cdot 077)$. Serum $25(\mathrm{OH}) \mathrm{D}$ levels were, on average, $17 \mathrm{nmol} / 1$ lower in participants with Fitzpatrick skin type V-VI compared with skin types I-IV (Table 3).

\section{Stepwise regression model}

Factors found to be significantly associated with $25(\mathrm{OH}) \mathrm{D}$ in univariate analyses were included in a stepwise elimination regression model (Table 4). Serum SHBG, creatinine, daily sun exposure measured by UV dosimetry, a holiday taken in the most recent summer period, multivitamin use, spending $>2 \mathrm{~h}$ daily in the sun in summer, Fe concentrations, height and the sun tanning attitude score were independently associated with higher serum 25(OH)D levels. Factors independently associated with lower serum 25(OH)D were season (autumn, winter or spring compared with summer) and fat mass. The final model explained $56 \%$ of the variation in serum $25(\mathrm{OH}) \mathrm{D}$.

\section{Discussion}

The Safe-D study is the first to evaluate vitamin D status in young women recruited through Facebook advertising, a novel, nontraditional method of recruitment. The prevalence of VDD in 16-25-year-old females was $26 \%$. The following variables were 
found to be positively associated with serum 25(OH)D (Table 4): SHBG levels, creatinine levels, personal sun exposure in the previous 2 weeks, holiday taken in the most recent summer period, blood drawn in the summer season, multivitamin use, reporting spending more than $2 \mathrm{~h}$ in the sun in summer on a typical day, Fe levels, body height and having a positive attitude towards sun tanning. Fat mass was negatively correlated with serum 25(OH)D. Our final model was able to explain more than $50 \%$ of the variation in serum $25(\mathrm{OH}) \mathrm{D}$ concentrations in a community sample of 348 healthy young women. By contrast, Kimlin et $a l .{ }^{(7)}$ were able to explain $40 \%$ of the variance in 25(OH)D levels in 1002 Australians aged 18-75 years, living across $24^{\circ}$ of latitude. We found that $26 \%$ of the young women studied were vitamin D deficient, which is in close agreement with the current literature that has reported prevalence rates of $21-27 \%^{(5,25)}$. A US report found that $25(\mathrm{OH}) \mathrm{D}$ levels were significantly lower in young adults compared with adults aged older than 60 years of age ${ }^{(26)}$. Collectively, these findings suggest that VDD may be as common in adolescents and young adults as in older populations, who are usually considered the most at risk for VDD. The lower prevalence of VDD in older adults may be, in part, due to the higher vitamin D supplement use in older adults. Current Australian Bureau of Statistics (ABS) data suggest that $20 \%$ of adults aged $>75$ years have VDD compared with $31 \%$ in 18-34 year olds. However, $14 \%$ of older adults use vitamin D supplements compared with $<3 \%$ in $18-34$ year olds ${ }^{(27)}$. Nonetheless, these results support the need for future vitamin D research, including supplementation trials, in this currently understudied demographic.

We found no association between $25(\mathrm{OH}) \mathrm{D}$ and education levels or socioeconomic status in the final model, suggesting that they are not strong correlates of $25(\mathrm{OH}) \mathrm{D}$ in this demographic. In univariate analyses, $25(\mathrm{OH}) \mathrm{D}$ was positively associated with socioeconomic status, whereas 25(OH)D concentrations were lower in participants receiving further education. It should be noted that there was no association between education levels and SEIFA percentile in the current study. The SEIFA index used in this study is calculated from a number of socioeconomic status variables including, but not limited to, education, assets, income, debt, occupation and housing details. The education aspect of the SEIFA index looks at the proportion of individuals with an education of year 11 (approximately 16-17 years old) or lower. Due to the age range studied and cohort demographics, participants in the Safe-D study in current education would be in late high school (year 11-12) or in tertiary/further education. The discrepancy between the education measures is likely the reason for the contradictory direction of the association between socioeconomic status and $25(\mathrm{OH}) \mathrm{D}$, as well as between $25(\mathrm{OH}) \mathrm{D}$ and education level.

As expected, serum 25(OH)D was inversely associated with PTH. Serum 25(OH)D was positively associated with serum creatinine in the final model, a marker of renal function, which has been previously reported ${ }^{(9,28)}$. Vieth et al ${ }^{(9)}$ found the same association in participants $<51$ years old $(P<0 \cdot 001)$, but not in participants older than 70 years of age. Treatment with calcitriol has been shown to cause an increase in creatinine, but the mechanism is unclear ${ }^{(29)}$. The lack of association between
$25(\mathrm{OH}) \mathrm{D}$ and age in the final model is likely due to the narrow age range studied. The Safe-D participants were primarily Caucasian and Australian-born, which might explain the lack of an observed association between $25(\mathrm{OH}) \mathrm{D}$ and country of birth in the final model (Table 4), despite the significant association observed in univariate analyses.

Serum 25(OH)D showed a seasonal variation, which has been consistently demonstrated and is predominantly due to increased ambient UVR in summer, thereby facilitating cutaneous vitamin D synthesis ${ }^{(30-33)}$. Although season plays an important role in influencing vitamin D status, behavioural factors also contribute ${ }^{(12)}$. We demonstrated that daily sun exposure, a higher sun tanning attitude score, spending $>2 \mathrm{~h}$ daily in the sun in summer and taking a holiday in the summer period, as well as height were positively associated with $25(\mathrm{OH}) \mathrm{D}$ in the final model. The association between $25(\mathrm{OH}) \mathrm{D}$ and height has been described previously in young American women aged $16-22$ years $^{(34)}$. It correlates with a larger body surface area and therefore a greater potential capacity to synthesise vitamin D. In addition to increasing vitamin D synthesis, UVR exposure is the cause of $95-99 \%$ of skin cancers. The association between $25(\mathrm{OH}) \mathrm{D}$ and spending $>2 \mathrm{~h}$ in the sun is particularly striking as this amount of sun exposure would be considered excessive and likely increase the risk of skin cancer significantly. Melanoma remains the most common cancer among 15-24-year-old Australians; therefore, it is crucial that efforts are made to achieve a balance between safe sun exposure, to minimise the risk of skin cancer, and sufficient sunlight exposure to achieve adequate vitamin D status ${ }^{(35,36)}$.

Only $9 \%$ of samples tested had detectable $25(\mathrm{OH}) \mathrm{D}_{2}$, suggesting that plant-based dietary sources of supplemental forms of vitamin $\mathrm{D}_{2}$ contribute very little to circulating $25(\mathrm{OH}) \mathrm{D}$ in young Australians. In contrast, a US population-based study found that individuals with a vitamin D intake of $>5 \mu \mathrm{g} / \mathrm{d}$ had significantly higher $25(\mathrm{OH}) \mathrm{D}$ levels ${ }^{(26)}$. This observation suggests that a possible approach to improve vitamin D levels might be to adopt more active food-fortification strategies. Alternatively, increasing total vitamin D intake with supplementation is a strategy that has been demonstrated to improve $25(\mathrm{OH}) \mathrm{D}$ levels ${ }^{(22)}$. In Australia, multivitamins are the most commonly used dietary supplement and contain about 5-10 $\mu \mathrm{g}$ (200-400 IU) vitamin $\mathrm{D}^{(37)}$. We demonstrated that participants who reported taking a multivitamin had approximately $12 \mathrm{nmol} / \mathrm{l}$ higher $25(\mathrm{OH}) \mathrm{D}$ levels in the final model. Multivitamins have been shown to be safe to use; however, data on the benefits of multivitamin use in the general population are limited ${ }^{(38,39)}$. It is likely that we did not find a significant association between $25(\mathrm{OH}) \mathrm{D}$ and vitamin D supplement use due to the low proportion of use (approximately $8 \%$ ) and data were limited to the previous 2 weeks, rather than the previous month, for example. In Australia, most vitamin D supplements contain $25 \mu \mathrm{g}$ (1000 IU) vitamin D. Randomised-controlled trials would provide an opportunity to gain insights into the potential benefits of a multivitamin or vitamin $\mathrm{D}$ supplementation on vitamin D status and health outcomes in young women ${ }^{(24)}$.

The association between $25(\mathrm{OH}) \mathrm{D}$ and Fe levels is consistent with previous literature, suggesting that low 25(OH)D levels are associated with an increased risk of anaemia ${ }^{(40,41)}$. 
Haeme-bound $\mathrm{Fe}$ is used in the hydroxylation of vitamin $\mathrm{D}$ metabolites by the cytochrome $\mathrm{P} 450$ enzymes, providing a probable link between vitamin D and Fe metabolism ${ }^{(42)}$. Other proposed links between vitamin D and Fe status include vitamin D modulating inflammation, stimulating erythropoiesis, changes in hepcidin levels and associations with fibroblast growth factor $23^{(43,44)}$.Vitamin D supplementation trials may be able to resolve whether increasing $25(\mathrm{OH}) \mathrm{D}$ is beneficial to $\mathrm{Fe}$ status in young women.

We demonstrated that serum 25(OH)D levels were inversely associated with fat mass. The relationship between reduced $25(\mathrm{OH}) \mathrm{D}$ and obesity has consistently been reported and is commonly explained by increased $25(\mathrm{OH}) \mathrm{D}$ storage in adipose tissue as vitamin D metabolites are lipophilic, thereby reducing circulating concentrations ${ }^{(5,8,45,46)}$. Other mechanisms for reduced $25(\mathrm{OH}) \mathrm{D}$ levels with higher fat mass may be more specific to personal choices that reduce personal sun exposure, such as reduced outdoors activity or covering up, limiting vitamin D synthesis. The increasing prevalence of obesity in young women is likely to continue to contribute towards the prevalence of $\mathrm{VDD}^{(47)}$.

Serum 25(OH)D was positively associated with SHBG levels, which has been demonstrated to increase with COC oestrogen dose $^{(48)}$. In addition, COC use was associated with $19 \mathrm{nmol} / \mathrm{l}$ higher 25(OH)D levels in univariate analysis, which is in agreement with previous literature ${ }^{(10,49,50)}$. Harmon et al. ${ }^{(10)}$ recently found that COC use was associated with a $20 \%$ increase in $25(\mathrm{OH})$ D levels in 1662 African American women aged 23-34 years. Some studies have suggested that vitamin D binding protein (DBP) levels increase with COC use, varying the proportion of free and protein-bound $25(\mathrm{OH}) \mathrm{D}^{(49,50)}$. Alternatively, increased DBP binding may protect $25(\mathrm{OH}) \mathrm{D}$ from 24-hydroxylation, thereby increasing circulating $25(\mathrm{OH}) \mathrm{D}^{(49,50)}$. The use of COC should be taken into account when interpreting $25(\mathrm{OH}) \mathrm{D}$ results and a review of vitamin $\mathrm{D}$ status might be considered when a young woman ceases COC use. The latter is particularly important for women planning to conceive, where ceasing COC use may further exacerbate VDD and affect pregnancy outcomes adversely.

The Safe-D study has a number of methodological strengths. We successfully recruited a broadly representative sample of young women and were able to produce a data set of generally healthy young women through extensive health data collection ${ }^{(51)}$. In addition, LC-MS/MS was employed by National Association of Testing Authorities, Australia, accredited laboratory to assay serum $25(\mathrm{OH}) \mathrm{D}$ as this method has the highest sensitivity and specificity compared with other $25(\mathrm{OH}) \mathrm{D}$ assays and is therefore often considered the current 'gold standard' for $25(\mathrm{OH}) \mathrm{D}$ measurement ${ }^{(52-54)}$. The objective measurement of sun exposure through UV dosimeters has previously been shown to be a feasible and more accurate measure of time spent outdoors compared with self-reported data ${ }^{(55)}$. Finally, the study could explain $56 \%$ of the variability in $25(\mathrm{OH}) \mathrm{D}$ levels by assessing a wide range of clinical, behavioural and lifestyle factors associated with 25(OH)D and indicated that SHBG levels, creatinine levels, sun exposure, holiday in the most recent summer period, season, fat mass, multivitamin use, Fe levels, height and attitudes towards sun tanning were the major sources of vitamin D status in young women.
Our study is not without limitations. A number of countries use a cut-off of $<30 \mathrm{nmol} / 1$ to define VDD. Due to the small proportion of participants with serum $25(\mathrm{OH}) \mathrm{D}<30 \mathrm{nmol} / 1(20 / 348 ; 6 \%)$, it is difficult to make conclusive judgements about associations between health outcomes within this concentration range. Although the cohort was broadly representative of young Victorian women $^{(51)}$, there were some slight differences. Participants were primarily Australian born (84v. 78\%), had a higher education level (67 v. 43\%) and more resided in urban areas (91 v. 79\%) compared with the ABS Census of Population and Housing 2011 data in 16-25-year-old Victorian females. The underrepresentation of overseas-born individuals and those from regional areas was likely due to language/cultural barriers and difficulties travelling to the study site centre in Melbourne, respectively. The greater proportion of higher educated participants is common in volunteer samples in research and may also be contributed to by the close vicinity of a number of universities to the study site centre. The Victorian Population Health Survey 2011-2012 found that 14.6\% of 18-24-year-old Victorian women were current smokers and $21.9 \%$ were insufficiently active, which are similar to our results (9.5 and $28.7 \%$, respectively) ${ }^{(56)}$. In terms of body composition, $18.2 \%$ of Victorians were considered overweight or obese in the 2011-2012 survey, which was lower than our data (28.5\%), which could potentially reflect population trends in obesity levels since the precious census ${ }^{(47)}$. Nonetheless, slight differences in participant demographics are not necessarily biologically significant. Due to loss, damage or inaccurate use of UV dosimeters, the number with eligible UV data was reduced, thus reducing analytical power. We measured a large number of possible $25(\mathrm{OH}) \mathrm{D}$ correlates, which may lead to identifying significant correlations by chance alone. By using a stepwise elimination regression model in our final model we could present the variables that were the strongest statistical determinants of $25(\mathrm{OH}) \mathrm{D}$. This is also why weaker correlates may have been significant correlated with $25(\mathrm{OH}) \mathrm{D}$ in univariate analyses alone as confounding variables may have been eliminated from the final model. Finally, due to the study's cross-sectional nature, causation cannot be inferred; however, we are examining these relationships in part B of the Safe-D study ${ }^{(24)}$.

In conclusion, VDD was found to be as prevalent in young women as reported previously in older Australian adults. We were able to explain over half of the variation in serum $25(\mathrm{OH}) \mathrm{D}$ levels using sun exposure-related, biochemical and anthropometric variables. A better understanding of the factors influencing vitamin D status may help better identify individuals at increased risk of VDD. Our findings support the need for further vitamin D research specifically in young women and the need to address modifiable risk factors for VDD such as low sun exposure and obesity. The feasibility of safely improving vitamin D levels through lifestyle interventions in young women requires further attention in this currently understudied demographic.

\section{Acknowledgements}

The authors thank the participants who took part in the Safe-D study. The authors also thank the Safe-D chief investigators Associate Professor Marie Pirotta, Professor Anthony Jorm, 
Associate Professor Shanton Chang and Professor George Varigos as well as associate investigator Professor Kim Bennell, study coordinator Ms Adele Rivers and other members of the Safe-D research team. The authors thank the Young Female Health Initiative (YFHI) associate investigators Dr Yasmin Jayasinghe, Dr Catherine Segan, Dr Asvini Subasinghe and past YFHI coordinator Dr Elisa Young. The authors thank Anna Scobie, Marjan Tabesh, Miaowen Zhou, Lauren Gilbert and Skye Maclean for assisting with the Safe-D study. The authors would like to acknowledge the following people for their help with various components of the study: Adrian Bickerstaffe (The University of Melbourne); Maria Bisignano (Melbourne Health Shared Pathology Service); Alison Brodie (Queensland University of Technology); Dr Peter Gies (Australian Radiation Protection and Nuclear Safety Agency); Dr Ashwini Kale (The University of Melbourne); Dr Kerryn King (Australian Radiation Protection and Nuclear Safety Agency); and Jen Makin (Cancer Council Victoria).

The Safe-D study was funded by the Australian National Health and Medical Research Council (NHMRC) project grant APP1049065. The Safe-D study (part B) has received in-kind support from Swisse Wellness. Swisse Wellness did not play a role in study design, the implementation of these studies or the interpretation of the findings.

J. D. W. conceived the study. E. T. C. participated in the design of the study, establishment of the study methods, data collection and drafted the manuscript. J. D. W., S. M. G., A. G. and N. J. R. are study investigators and were involved in study design, study coordination and helped draft the manuscript. A. G. is the study statistician and was involved in sample size and power calculations and also advised on the statistical analysis of the data. All authors read, contributed to and approved the final manuscript.

The authors declare that there are no conflicts of interest.

\section{Supplementary material}

For supplementary material/s referred to in this article, please visit https://doi.org/10.1017/S0007114517002021

\section{References}

1. Holick M (2015) Vitamin D and brain health: the need for vitamin D supplementation and sensible sun exposure. J Intern Med 277, 90-93.

2. Feldman D, Pike JW \& Adams JS (2011) Vitamin D: TwoVolume Set. New York: Elsevier Academic Press.

3. Sawyer SM, Afifi RA, Bearinger LH, et al. (2012) Adolescence: a foundation for future health. Lancet 379, 1630-1640.

4. Patton GC, Sawyer SM, Santelli JS, et al. (2016) Our future: a Lancet commission on adolescent health and wellbeing. Lancet 387, 2423-2478.

5. Daly RM, Gagnon C, Lu ZX, et al. (2012) Prevalence of vitamin D deficiency and its determinants in Australian adults aged 25 years and older: a national, population-based study. Clin Endocrinol 77, 26-35.

6. Mousa A, Misso M, Teede H, et al. (2016) Effect of vitamin D supplementation on inflammation: protocol for a systematic review. BMJ Open 6, e010804.

7. Kimlin MG, Lucas RM, Harrison SL, et al. (2014) The contributions of solar ultraviolet radiation exposure and other determinants to serum 25-hydroxyvitamin D concentrations in Australian adults: the AusD Study. Am J Epidemiol 179, 864-874.

8. Black D \& Rosen C (2016) Clinical practice. Postmenopausal osteoporosis. N Engl J Med 374, 254-262.

9. Vieth R, Ladak Y \& Walfish PG (2003) Age-related changes in the 25-hydroxyvitamin $\mathrm{D}$ versus parathyroid hormone relationship suggest a different reason why older adults require more vitamin D. J Clin Endocrinol Metab 88, 185-191.

10. Harmon QE, Umbach DM \& Baird DD (2016) Use of estrogencontaining contraception is associated with increased concentrations of 25-hydroxy vitamin D. J Clin Endocrinol Metab 101, 3370-3377.

11. Pasco JA, Henry MJ, Nicholson GC, et al. (2009) Behavioural and physical characteristics associated with vitamin D status in women. Bone 44, 1085-1091.

12. van der Mei IA, Ponsonby A-L, Engelsen O, et al. (2007) The high prevalence of vitamin D insufficiency across Australian populations is only partly explained by season and latitude. Environ Health Perspect 115, 1132.

13. Pasco JA, Henry MJ, Nicholson GC, et al. (2001) Vitamin D status of women in the Geelong Osteoporosis Study: association with diet and casual exposure to sunlight. Med J Aust 175, 401-405.

14. Callegari ET, Reavley N, Garland SM, et al. (2015) Vitamin D status, bone mineral density and mental health in young Australian women: the Safe-D study. J Public Health Res $\mathbf{4}$, 152-156.

15. Fitzpatrick TB (1988) The validity and practicality of sun-reactive skin types I through VI. Arch Dermatol 124, 869.

16. Brown WJ, Burton NW, Marshall AL, et al. (2008) Reliability and validity of a modified self-administered version of the Active Australia physical activity survey in a sample of mid-age women. Aust N Z J Public Health 32, 535-541.

17. Giles G \& Ireland P (1996) Dietary Questionnaire for Epidemiological Studies (Version 2). Melbourne: Cancer Council Victoria.

18. Hill D, White V, Marks R, et al. (1992) Melanoma prevention: behavioral and nonbehavioral factors in sunburn among an Australian urban population. Prev Med 21, 654-669.

19. Cancer Council Australia (2007) Slip Slop Slap Seek Slide. http://www.cancer.org.au/preventing-cancer/sun-protection/ campaigns-and-events/slip-slop-slap-seek-slide.html (accessed January 2017)

20. Dwyer T, Blizzard L, Ashbolt R, et al. (2002) Cutaneous melanin density of Caucasians measured by spectrophotometry and risk of malignant melanoma, basal cell carcinoma, and squamous cell carcinoma of the skin. $\mathrm{Am} \mathrm{J}$ Epidemiol 155, 614-621.

21. Diamond TH, Eisman JA, Mason RS, et al. (2005) Vitamin D and adult bone health in Australia and New Zealand: a position statement. Med J Aust 182, 281-285.

22. Nowson CA, McGrath JJ, Ebeling PR, et al. (2012) Vitamin D and health in adults in Australia and New Zealand: a position statement. Med J Aust 196, 686-687.

23. Pink B (2011) Socio-Economic Indexes for Areas (SEIFA) technical paper. Catalogue no. 2033.0. 55.001. Canberra, Australia: ABS.

24. Tabesh M, Garland S, Gorelik A, et al. (2016) Improving vitamin D status and related health in young women: the Safe-D study - part B. JMIR Res Protoc 5, e80.

25. Gill TK, Hill CL, Shanahan EM, et al. (2014) Vitamin D levels in an Australian population. BMC Public Health 14, 1.

26. Schleicher RL, Sternberg MR, Looker AC, et al. (2016) National estimates of serum total 25-hydroxyvitamin D and metabolite concentrations measured by liquid chromatography-tandem mass spectrometry in the US population during 2007-2010. J Nutr 146, 1051-1061. 
27. Australian Bureau of Statistics (2014) Australian Health Survey: Biomedical Results for Nutrients, 2011-12. Canberra: Australian Bureau of Statistics.

28. Shirazi L, Almquist M, Malm J, et al. (2013) Determinants of serum levels of vitamin D: a study of life-style, menopausal status, dietary intake, serum calcium, and PTH. BMC Womens Health 13, 33.

29. Andreev E, Koopman M \& Arisz L (1999) A rise in plasma creatinine that is not a sign of renal failure: which drugs can be responsible? J Intern Med 246, 247-252.

30. Webb AR, Kline L \& Holick MF (1988) Influence of season and latitude on the cutaneous synthesis of vitamin $\mathrm{D}_{3}$ : exposure to winter sunlight in Boston and Edmonton will not promote vitamin $\mathrm{D}_{3}$ synthesis in human skin. J Clin Endocrinol Metab 67, 373-378.

31. Mithal A, Wahl D, Bonjour J-P, et al. (2009) Global vitamin D status and determinants of hypovitaminosis D. Osteoporos Int 20, $1807-1820$.

32. Looker AC, Dawson-Hughes B, Calvo M, et al. (2002) Serum 25-hydroxyvitamin D status of adolescents and adults in two seasonal subpopulations from NHANES III. Bone 30, 771-777.

33. Gies P (2003) Australia has more than enough solar UV radiation. Clin Exp Optom 86, 71-73.

34. Kremer R, Campbell PP, Reinhardt T, et al. (2009) Vitamin D status and its relationship to body fat, final height, and peak bone mass in young women. J Clin Endocrinol Metab 94, 67-73.

35. Australian Institute of Health and Welfare \& Australasian Association of Cancer Registries (2008) Cancer in Australia: An Overview, 2008, Cancer Series no 46, Cat no CAN 42. Canberra: AIHW

36. Armstrong B \& Kricker A (1993) How much melanoma is caused by sun exposure? Melanoma Res 3, 395-402.

37. Australian Bureau of Statistics (2014) Australian Health Survey: Nutrition First Results - Food and Nutrients, 2011-12. Canberra: Australian Bureau of Statistics.

38. Huang H-Y, Caballero B, Chang S, et al. (2006) Multivitamin/ mineral supplements and prevention of chronic disease. Evid Rep Technol Assess (Full Rep) 139, 1-117.

39. Macpherson H, Pipingas A \& Pase MP (2013) Multivitaminmultimineral supplementation and mortality: a meta-analysis of randomized controlled trials. Am J Clin Nutr 97, 437-444.

40. Monlezun DJ, Camargo CA Jr, Mullen JT, et al. (2015) Vitamin D status and the risk of Anemia in community-dwelling adults: results from the National Health and Nutrition Examination Survey 2001-2006. Medicine 94, e1799.

41. Blanco-Rojo R, Pérez-Granados AM, Toxqui L, et al. (2013) Relationship between vitamin D deficiency, bone remodelling and iron status in iron-deficient young women consuming an iron-fortified food. Eur J Nutr 52, 695-703.
42. Jones G, Prosser DE \& Kaufmann M (2014) Cytochrome P450mediated metabolism of vitamin D. J Lipid Res 55, 13-31.

43. Smith EM \& Tangpricha V (2015) Vitamin D and anemia: insights into an emerging association. Curr Opin Endocrinol Diabetes Obes 22, 432-438.

44. Smith EM, Alvarez JA, Kearns MD, et al. (2017) High-dose vitamin $\mathrm{D}_{3}$ reduces circulating hepcidin concentrations: a pilot, randomized, double-blind, placebo-controlled trial in healthy adults. Clin Nutr 36, 980-985.

45. Blum M, Dolnikowski G, Seyoum E, et al. (2008) Vitamin $\mathrm{D}_{3}$ in fat tissue. Endocrine 33, 90-94.

46. Wortsman J, Matsuoka LY, Chen TC, et al. (2000) Decreased bioavailability of vitamin D in obesity. Am J Clin Nutr $\mathbf{7 2}$, 690-693.

47. Moodie AR (2008) Australia: the healthiest country by 2020. Med J Aust 189, 588-590.

48. Zimmerman Y, Eijkemans M, Bennink HC, et al. (2014) The effect of combined oral contraception on testosterone levels in healthy women: a systematic review and meta-analysis. Hum Reprod Update 20, 76-105.

49. Møller UK, Jensen LT, Mosekilde L, et al. (2013) Increased plasma concentrations of vitamin D metabolites and vitamin D binding protein in women using hormonal contraceptives: a cross-sectional study. Nutrients 5, 3470-3480.

50. Bouillon R, Baelen HV \& Moor PD (1977) The measurement of the vitamin D-binding protein in human serum. $J$ Clin Endocrinol Metab 45, 225-231.

51. Fenner Y, Garland SM, Moore EE, et al. (2012) Web-based recruiting for health research using a social networking site: an exploratory study. J Med Intern Res 14, e20.

52. Fraser WD \& Milan AM (2013) Vitamin D assays: past and present debates, difficulties, and developments. Calcif Tissue Int 92, 118-127.

53. El-Khoury JM, Reineks EZ \& Wang S (2011) Progress of liquid chromatography-mass spectrometry in measurement of vitamin D metabolites and analogues. Clin Biochem $\mathbf{4 4}$, 66-76.

54. Ashwell M, Stone EM, Stolte H, et al. (2010) UK Food Standards Agency Workshop Report: an investigation of the relative contributions of diet and sunlight to vitamin D status. Br J Nutr 104, 603-611.

55. Køster B, Søndergaard J, Nielsen JB, et al. (2015) Feasibility of smartphone diaries and personal dosimeters to quantitatively study exposure to ultraviolet radiation in a small national sample. Photodermatol Photoimmunol Photomed 31, 252-260.

56. Department of Health (2014) Victorian Population Health Survey 2011-12, Survey Findings. Melbourne: State Government of Victoria. 